\title{
TRANSVER OS ESTUDOS BRASILEIROS: QUEM ESTUDA QUEM E COMO?
}

A RIEB chega ao seu número 77 e novamente se apresenta como espaço de análise da realidade brasileira por meio de suas e de seus intérpretes. Congratulamo-nos com todas as pessoas que trabalharam para esta publicação.

As fotos que ilustram esta edição fazem parte da documentação de Mário de Andrade, mais especificamente de seu fundo no Arquivo do IEB. Foram presenteadas pelas alunas ao então jovem professor Mário entre os anos I9Io e I930. São evidências da polifonia dos fundos e coleções e servem para refletirmos, por exemplo, sobre presenças e ausências, par conceitual que perpassa toda esta edição. São documentos a partir dos quais se indaga, por exemplo, sobre a dimensão pública e privada da fotografia e das pessoas fotografadas. Nas dedicatórias - que contextualizam as fotos enquanto objeto e gesto - entrevê-se a relação pedagógica. Uma homenagem ao ensino, ao professorado e aos alunos ${ }^{\mathrm{I}}$. Aliás, alunas, todas alunas - e brancas, provavelmente cisgênero. Diante do consenso sobre a importância da educação, ressoa a pergunta: quem estuda, o que estuda; quem e como? São questões refletidas nos artigos que passamos a apresentar.

Em "Pão, fama e outras fomes: uma leitura de Carolina Maria de Jesus e Clarice Lispector”, Marise Hansen observa a relação entre as autoras e seus contextos. A análise se desenvolve a partir das obras Laços de família, de Clarice Lispector, e Quarto de despejo, de Carolina Maria de Jesus, ambas lançadas em I960 e pela mesma editora. Entre diversas outras questões, Hansen problematiza a fome de palavra e o modo de gritar das autoras e suas representações literárias. Na relação impreterível entre as escritas e o contexto político dos anos I960, Marise Hansen remarca que a ditadura civil-militar chegou a impor censura à voz literária de Carolina Maria de Jesus, violação que acometeu outros intérpretes do Brasil, como se observa no artigo seguinte.

Em “Adoniran Barbosa e a língua certa do povo", Adriano de Paula Rabelo pontua como o compositor recriava artisticamente a fala popular para vocalizar os sujeitos da cidade de São Paulo entre os anos I930 e I960. O autor problematiza a relação entre a escolarização, as variações linguísticas identificadas às classes populares e a poética do artista. Também explicita como este é herdeiro e promotor do espírito modernista, que se opõe ao conservadorismo, à fixidez das normas e ao preconceito linguístico. Em virtude desse preconceito (que exprime os

I Homenagem que reiteramos aqui, diante do contexto atual de desafios para a educação, elaboração e valorização do conhecimento e das pessoas que participam desses processos. 
lugares de importância conferidos aos sujeitos) é que a obra de Adoniran chegou a ser censurada nos anos I960.

O terceiro artigo é "Educação, currículo e diferenças: uma análise dos povos indígenas na educação escolar de Mato Grosso do Sul, Brasil”, de Sanderson Pereira Leal e Walter Guedes da Silva. O preconceito e a violência também são problematizados e se observa como os temas relacionados à memória e história dos povos indígenas figuram nos conteúdos curriculares. Tomando por base a Lei Federal n. II.645/08 - que institui a obrigatoriedade do estudo da história e cultura afro-brasileira e indígena -, os autores analisam o currículo do ensino básico da educação pública no estado de Mato Grosso do Sul (MS), onde se concentra a segunda maior população indígena do país (conforme o Instituto Brasileiro de Geografia e Estatística - IBGE).

O quarto texto também utiliza o contexto da educação para observar relações de exclusão, preconceito e violência que se instituem na sociedade brasileira. Trata-se de "Educação básica e o acesso de transexuais e travestis à educação superior", de Tatiane Lima. A autora analisa a relação entre os debates sobre gênero e sexualidade (durante a educação básica) e a possibilidade de que pessoas transexuais e travestis continuem sua formação escolar, tomando em conta os recentes marcos políticos e jurídicos relativos às pessoas da comunidade LGBT $^{2}$ no Brasil. Também problematiza o que é necessário à estrutura da educação para que essas pessoas - ainda muito marginalizadas no sistema atual, conforme os dados explicitam - tenham espaço na educação formal.

O artigo seguinte tem como título "Sobre 'ser caboclo': as vozes de caboclos do Oeste catarinense", de autoria de Maria de Souza, Luci dos Santos Bernardi e Jorge Alejandro Santos. A partir de um inventário a respeito da cultura imaterial cabocla da região do Oeste de Santa Catarina, são identificados traços específicos da visão de mundo desses sujeitos. Destaca-se, por exemplo, a religiosidade popular em torno da figura do monge João Maria de Agostini. Os autores problematizam os chamados costumes e tradições híbridas, remarcando expressões de saberes e fazeres coletivos, como artefatos e construções, modos de comer e a relação com o ambiente natural.

O sexto artigo, de Alfredo Cesar Melo, tem como título "O texto e o pacto: estratégias discursivas em Casa-grande ersenzala para pactuar a democracia racial”. O autor toma a obra e, por meio dela, observa como a produção de Gilberto Freyre pode ser pensada a partir da dimensão performativa e pedagógica da democracia racial. Explicita também como ambas as dimensões estão implicadas na elaboração processual de Freyre (e sua sociologia) e como sua produção impacta a própria ideia de democracia racial, no seu tempo e depois.

Em "O Brasil e os brasis no Antropoceno: bifurcações à vista”, Stelio Marras apresenta uma série de indagações, à luz do contexto atual, em que não se pode dissimular os constrangimentos diante da situação ecossocial. Argumentando em favor da associação impreterível entre os direitos sociais e ambientais, diante do Antropoceno, Marras problematiza a condição do Brasil (ou dos brasis) para

2 Lésbicas, gays, bissexuais, travestis, transexuais (PAIVA; MELLO, 20I3, p. 7) e transgêneros. Trata-se da sigla adotada no âmbito das políticas públicas brasileiras. 
liderar ou participar naquilo que identifica como a passagem da modernização para a contramodernização.

Em "Anna Maria Maiolino sob a perspectiva da crítica de processo: vestígios da criação", Vinícius de Oliveira Gonçalves e Cecilia Almeida Salles debatem a possibilidade de análise da obra da artista, relacionando-a ao seu processo de criação. Situam também a relevância em se propor uma teoria crítica de processo para a compreensão da obra de arte e, nessa perspectiva, destacam aspectos do percurso artístico e das redes culturais de Anna Maria Maiolino.

No artigo “'Esquecer Williams?': materialismo cultural, estruturas de sentimento e pesquisas sobre música popular no Brasil”, Sheyla Castro Diniz destaca que a hipótese cultural de estruturas de sentimento, desenvolvida por Raymond Williams, tem sido bastante retomada em pesquisas no Brasil. A respeito disso, no entanto, vê uma desarticulação entre os usos da noção e a concepção de materialismo histórico no mesmo autor. Defendendo o aprofundamento no movimento teórico e metodológico de Williams, a autora retoma aspectos de seu debate crítico e discute o potencial de suas reflexões para a pesquisa em música popular.

Fechando a seção de artigos, Denilson Lopes, em "Pequeno monstro e leviano: infância e adolescência de Mário Peixoto”, toma por base trechos de diário inédito de Peixoto, chamado de Cadernos verdes. Sinalizando para uma tensão entre o diário e a memória, o autor explica que o documento é composto de duas partes. A primeira contém a narrativa de Mário Peixoto, e a segunda é constituída por cartas trocadas com sua prima. Com base nessa fonte, o autor situa fatos do cotidiano e lança hipóteses sobre essa etapa da vida do escritor e diretor.

A seção Resenhas da RIEB apresenta dois diferentes textos, elaborados a partir da obra Pensamento feminista brasileiro: formação e contexto, organizada por Heloisa Buarque de Hollanda, publicada em 2019.

Em “Estudos feministas brasileiros: (re)conhecer e continuar", Renata Cardozo Padilha explica a estrutura da obra e a sequência temática nas quatro partes do livro, conforme seus títulos e suas autoras. Destacando e citando trechos, Padilha pontua aspectos fundamentais da obra, por exemplo, a respeito do feminismo e as interseccionalidades. Fornece também um olhar crítico ao pôr em relevo, por exemplo, que há pouco debate a respeito das questões que evolvem as pessoas LGBTQIA+3. Considerando a polifonia das autoras e seus estudos, Renata Cardozo Padilha argumenta ainda que a publicação é leitura fundamental para a compreensão da realidade brasileira, no passado e no presente.

Na resenha intitulada "Feminismo brasileiro como luta e epistemologia", Gleyce Kelly Heitor situa o livro em relação à produção de Heloisa Buarque de Hollanda e ao contexto histórico em que os feminismos e as diversas lutas das mulheres, suas questões, possibilidades e contingências emergem. Gleyce destaca que a publicação está atenta às condições atuais da nova geração e que, diante disso, visa contribuir com uma perspectiva histórica e conceitual dos feminismos. A autora observa

3 Lésbicas, gays, bissexuais, transexuais e travestis, queer, intersex, assexuais e mais. Sigla que exprime (com variações e acréscimos) possibilidades diversas e atuais a respeito da compreensão e da (auto)identificação quanto ao gênero e à sexualidade. 
uma predominância na representação das questões relativas ao sudeste do país e evidencia que as assimetrias regionais impactam a circulação do conhecimento. Em sua síntese, Gleyce Kelly Heitor afirma o livro organizado por Heloisa Buarque de Hollanda como um livro-luta.

Na seção Documentação, Mariana Diniz Mendes traz à baila os diários de Maria Isabel Silveira, documentos constantes no Fundo Valdomiro Silveira, cujo arquivo pessoal foi doado ao Instituto de Estudos Brasileiros (IEB) em 2006. Em seu texto, cujo título é “Diários de Maria Isabel Silveira: vestígio e inscrição de uma voz", a autora problematiza os silêncios a respeito da história das mulheres (PERROT, 2005), evidenciando que a profusão da documentação em questão é uma exceção. Destaca a importância das fontes, relacionando isso ao arquivamento, à elaboração da memória, às esferas de poder e legitimação. Em sua análise, Mariana faz ainda o cotejamento entre os originais e o livro publicado pela neta de Maria Isabel Silveira, observando neste a supressão do conteúdo político e do estilo verborrágico dos originais. Entre outros aspectos, a autora realça a importância dos diários como fonte da observação do universo material de seu contexto, alguns dos quais produtos da própria artesania de mulheres.

Do fim voltamos ao começo4. Na capa desta edição buscamos deixar registrado o respeito às mais de I70 mil vítimas brasileiras da covid-I9. E, novamente, convém refletir sobre presenças e ausências, sobre quem é sujeito e quem é objeto.

Diante desse conjunto, esperamos que desfrutem da RIEB 77 e que suas reflexões possam estimular novos caminhos de pesquisa e produção de conhecimento.

Fernando Paixão5, Inês Gouveia ${ }^{6}$, Luciana Suarez Galvão7

Editores

\section{REFERÊNCIAS}

PAIVA, Crístian; MELLO, Luiz. Apresentação - Políticas de gênero e sexualidade: pensando a cidadania e os direitos humanos de lésbicas, gays, bissexuais, travestis e transexuais. Revista de Ciências Sociais, Fortaleza, v. 44, n. I, jan.jun., 20I3, p. 7-9. Disponível em: http://www.periodicos.ufc.br/revcienso/ issue/view/I24. Acesso em: 4 nov. 2020.

PERROT, Michelle. As mulheres ou os silêncios da história. Bauru: Edusc, 2005.

\footnotetext{
4 Uma boa analogia com simbologias deste número 77, se assim o quisermos.

5 Universidade de São Paulo (USP, São Paulo, SP, Brasil).

6 Universidade de São Paulo (USP, São Paulo, SP, Brasil).

7 Universidade de São Paulo (USP, São Paulo, SP, Brasil).
} 


\section{SOBRE OS AUTORES}

FERNANDO PAIXÃO é docente do Instituto de Estudos Brasileiros da Universidade de São Paulo (IEB/USP).

fernando.paixao@usp.br

https://orcid.org/o0oo-00oI-5I57-I506

INÊS GOUVEIA é docente do Instituto de Estudos Brasileiros da Universidade de São Paulo (IEB/USP). inescgouveia@usp.br https://orcid.org/oooo-0003-4783-9033

LUCIANA SUAREZ GALVÃO é docente do Instituto de Estudos Brasileiros da Universidade de São Paulo (IEB/USP).

lsgalvao@usp.br https://orcid.org/0000-0003-I369-688X

Recebido em 4 de novembro de 2020 Aprovado em Io de novembro de 2020

PAIXÃO, Fernando; GOUVEIA, Inês; GALVÃO, Luciana Suarez. Transver os estudos brasileiros: quem estuda quem e como?. Revista do Instituto de Estudos Brasileiros, Brasil, n. 77, p. I3-I7, dez. 2020.

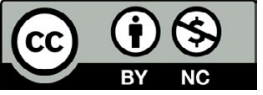

DOI: https://doi.org/Io.II606/issn.23I6-90IX.vii77pI3-I7 